\title{
Outcomes of Laparoscopic Cholecystectomy in Patients with End-Stage Renal Disease
}

\author{
Yahya Ekici, Tugan Tezcaner, Cem Aydoğan, Feza Y. Karakayalı, Gökhan Moray \\ Department of General Surgery, School of Medicine, Başkent University, Ankara, Turkey \\ Email: tugantezcaner@gmail.com
}

Received 28 August 2014; revised 27 September 2014; accepted 26 October 2014

Copyright $@ 2014$ by authors and Scientific Research Publishing Inc.

This work is licensed under the Creative Commons Attribution International License (CC BY). http://creativecommons.org/licenses/by/4.0/

(c) (i) Open Access

\section{Abstract}

Purpose: In this study, we aimed to discuss the laparoscopic cholecystectomy in patients with end stage renal disease compared to the general population. Materials and Methods: We retrospectively evaluated a group of patients with $(n=45)$ and without $(n=90)$ end-stage renal disease undergoing laparoscopic cholecystectomy. The groups were compared in terms of length of surgery; duration of hospitalization after surgery; use of blood derivatives; mortality rates; and perioperative, postoperative, and postdischarge complications. Results: Patients with end-stage renal disease exhibited a higher frequency of associated diseases; lower hemoglobin levels; and elevated alkaline phosphatase, blood urea nitrogen, and creatinine values. Statistically significant differences were found between the two groups regarding length of surgery (83.6 $\pm 14.88 \mathrm{vs} .71 .7$ \pm 11.42 minutes; $p<0.001)$; duration of hospitalization $(1.7 \pm 0.47$ vs. $1.4 \pm 0.31$ days; $p<0.001)$. In the group of patients with end-stage renal disease had significantly higher perioperative $(p=$ $0.011)$, postoperative $(p<0.001)$, and postdischarge complication $(p=0.011)$ rates. Among all patients with end-stage renal disease, $12(26.7 \%)$ were converted to an open procedure $(p<0.001)$. Conclusion: Despite higher complication rates of laparoscopic cholecystectomy in end-stage renal disease patients, laparoscopic cholecystectomy could be performed safely in patients with endstage renal disease with low levels of complications and no associated mortality.

\section{Keywords}

Laparoscopic Cholecystectomy, End-Stage Renal Disease, Hemodialysis

\section{Introduction}

The prevalence of gallstones in patients with end-stage renal disease (ESRD) undergoing dialysis is similar to the prevalence in the general population [1]-[3]. Cholecystectomy is considered as a treatment of choice for symptomatic gallstones [4]. With growing experience in the laparoscopic technique, it is possible to operate 
complicated scenarios like ESRD patients. Patients with ESRD receiving hemodialysis are usually immunocompromised and have varying degrees of associated coagulopathy [4]-[7]. The high incidence of concomitant disease in these patients (e.g., diabetes mellitus, liver disease, vascular disease, and amyloidosis) can affect the rates of perioperative and postoperative complications. The main causes of mortality and morbidity in ESRD patients are hemorrhage, infection, and delayed wound healing. Finally, the surgical intervention itself carries some pitfalls in this group of patients. Unfortunately, however, there is paucity of knowledge regarding laparoscopic cholecystectomy in ESRD patients.

In this study, we aimed to discuss the laparoscopic cholecystectomy in patients with end stage renal disease compared to the general population.

\section{Methods}

From July 2006 to October 2011, 135 consecutive patients who underwent laparoscopic cholecystectomy for symptomatic gallstones were divided into two groups depending on whether they had ESRD (case group) or not. Data was evaluated retrospectively. Of these 135 patients, 45 had ESRD and were on dialysis. All of the patients were provided medical history followed by physical examination. Demographic features, co-morbidities (in addition to ESRD), causes of renal failure, the American Society of Anesthesiologists (ASA) score and previous abdominal surgery were evaluated. Patients who had history of continuous ambulatory peritoneal dialysis (CAPD) were accepted as having previous abdominal surgery. Preoperative abdominal ultrasonography was performed in all patients, revealed gallstones with no additional pathologic findings except renal changes. Patients with acute cholecystitis, cholangitis, pancreatitis or suspected malignancy were excluded from the study. The study was approved by the Institutional Ethics Committee.

All patients underwent laparoscopic cholecystectomy with standard 4 port technique under general anesthesia. Pneumoperitoneum was created using a Veress needle and then first port was inserted supraumbilically. If a patient had previous abdominal surgery or CAPD operation, pneumoperitoneum was created through the first port supraumbilically by means of the open technique. Cholecystectomy was elective in all patients.

Preoperative laboratory findings, perioperative findings, duration of operation, length of hospital stay after surgery, complications and conversion to open rate were recorded prospectively.

The data were presented as means \pm standard deviation. Compliance to normal distribution of data was checked by using Kolmogorov-Smirnov test. Homogeneity of variances was evaluated with Levene's homogeneity test. A non-parametric test (Mann Whitney U test) was used for the data not normally distributed to compare mean values; categorical variables were analyzed with Pearson chi-square test or Fisher exact test. A value of 0.05 was taken as the level of significance.

\section{Results}

The study included 135 patients; 45 in the case group and 90 in the control group. Demographic and clinical characteristics can be seen in Table 1 . The mean age was $48.4 \pm 12.09$ in the case group and $49.6 \pm 17.08$ in the control group. There were 26 female patients (57.7\%) in the case group and $38(42.2 \%)$ in the control group. Eight patients (17\%) had hepatitis C virus (6; 13\%) and hepatitis B virus (2; 4\%) disease. Twenty-one of the ESRD patients (46\%) and 10 of the patients without ESRD (11.1\%) had a history of previous abdominal surgery (Table 1). In patients without ESRD, these consisted most frequently of gynecologic and lower abdominal operations; in patients with ESRD, these consisted of catheter placement for CAPD (24.4\%). The most common causes of renal failure were diabetes (17 patients; 37\%), hypertension (11 patients; $24 \%$ ), unknown (7 patients; 15\%), glomerulonephritis (5 patients; $11 \%$ ), and chronic pyelonephritis (5 patients; 11\%). Associated diseases (which were most frequently systemic arterial hypertension and diabetes mellitus) were observed in $75.5 \%$ of the patients in the ESRD group and in $42.2 \%$ of the patients without ESRD. Histopathological examination of gallbladder revealed chronic cholecystitis in all patients in both groups.

Preoperative laboratory data of two groups are shown in Table 2. In the case group, hemoglobin levels were significantly lower than the control group $(p<0.001)$. As expected, significantly higher alkaline phosphatase, blood urea nitrogen, and creatinine levels were assessed in the case group $(p<0.001, p<0.001, p<0.001$, respectively).

Clinical parameters are summarized in Table 3. Duration of surgery was $83.6 \pm 14.88$ minutes and was significantly higher in the case group $(p<0.001)$. The most frequent perioperative complications we observed were 
Table 1. Demographic and clinical characteristics of the groups.

\begin{tabular}{ccc}
\hline Parameter & With ESRD $(\mathrm{n}=45)$ & Without ESRD $(\mathrm{n}=90)$ \\
\hline Age (mean \pm st deviation) & $48.4 \pm 12.09$ & $49.6 \pm 17.08$ \\
Sex (M/F) & $19 / 26$ & $38 / 52$ \\
Chronic cholecystitis & 45 & 90 \\
ESRD treatment HD & 45 & - \\
ASA score 3 and greater & $45(100 \%)$ & $20(22 \%)$ \\
BMI $\left(\mathrm{kg} / \mathrm{m}^{2}\right)$ & $25 \pm 1.31$ & $27 \pm 1.24$ \\
HCV and HBV & $8(17 \%)$ & 0 \\
Associated diseases & $34(75.5 \%)$ & $31(34.4 \%)$ \\
Previous surgery & $21(46 \%)$ & $10(11.1 \%)$ \\
\hline
\end{tabular}

ASA, American Society of Anesthesiologists; BMI, body mass index; ESRD, end-stage renal disease; HCV, hepatitis C virus; HBV, hepatitis B virus; F, female; M, male; N, without ESRD.

Table 2. Preoperative laboratory data of patients with and without ESRD who underwent LC.

\begin{tabular}{cccc}
\hline Variable & With ESRD $(\mathrm{n}=45)$ & Without ESRD $(\mathrm{n}=90)$ & $p$ \\
\hline Hemoglobin $(\mathrm{g} / \mathrm{dL})$ & $10.4 \pm 1.02$ & $12.1 \pm 1.6$ & $<0.001$ \\
WBC $(/ \mu \mathrm{L})$ & $6624 \pm 1048$ & $7680 \pm 1554$ & 0.246 \\
Platelet $\left(\times 10^{3} / \mu \mathrm{L}\right)$ & $205.2 \pm 86.1$ & $250 \pm 78.3$ & 0.886 \\
BUN $(\mathrm{mg} / \mathrm{dL})$ & $64.3 \pm 16.2$ & $14.1 \pm 5$ & $<0.001$ \\
Creatinine (mg/dL) & $6.3 \pm 0.53$ & $0.86 \pm 0.2$ & $<0.001$ \\
Bilirubin (total) (mg/dL) & $0.73 \pm 0.26$ & $0.88 \pm 0.31$ & 0.160 \\
Bilirubin (direct) (mg/dL) & $0.27 \pm 0.1$ & $0.38 \pm 0.12$ & 0.157 \\
AST (IU/L) & $26.6 \pm 12.06$ & $29.2 \pm 15.18$ & 0.503 \\
ALT (IU/L) & $29.1 \pm 5.98$ & $33.2 \pm 13.98$ & 0.112 \\
ALP (IU/L) & $181.1 \pm 32.36$ & $78.2 \pm 27.72$ & $<0.001$ \\
PTT (second) & $13.3 \pm 0.8$ & $13 \pm 1.3$ & 0.226 \\
aPTT (second) & $29.9 \pm 1.7$ & $30.3 \pm 4.3$ & 0.636 \\
INR & $1.07 \pm 0.1$ & $1.01 \pm 0.1$ & 0.150 \\
\hline
\end{tabular}

perforation of the gallbladder (two patients with ESRD, 6\%; four patients without ESRD, 3.3\%) and bleeding from the liver bed (two patients with ESRD, 6\%; one patient without ESRD, 1.1\%). Twelve patients were converted to open in the case group; only 2 patients were converted to open in control group. Conversion rate was significantly higher in the case group $(p<0.001)$. The reason for conversion in both groups was difficult dissection because of adhesions. Comparing the duration of ESRD among patients who underwent laparoscopic cholecystectomy ( $n=33,65.6 \pm 55.4$ months) and those converted to open cholecystectomy $(n=12,71.2 \pm 35.9$ months), no statistically significant difference was found $(p=0.697)$. The duration of previous CAPD catheter was $16.5 \pm 8.7$ months. Postoperative complications were seen only in patients with ESRD and included three cases (6.6\%) of abdominal wall hematoma, two cases (4.4\%) of superficial trocar site infection, two cases (4.4\%) of wound dehiscence, and one case (2.2\%) of bile leakage from the cystic duct. One patient had bile drainage from abdominal drain on the second postoperative day underwent emergency endoscopic retrograde cholangiopancreaticography. Sphincterotomy and temporary biliary stent placement were performed. This patient was 
Table 3. Clinic parameters in patients with and without ESRD undergoing laparoscopic cholecystectomy.

\begin{tabular}{cccc}
\hline Variable & With ESRD $(\mathrm{n}=45)$ & Without ESRD $(\mathrm{n}=90)$ & $p$ \\
\hline Surgery time, min (mean) & $83.6 \pm 14.88$ & $71.7 \pm 11.42$ & $<0.001$ \\
Length of hospitalization, days (mean) & $1.7 \pm 0.47$ & $1.4 \pm 0.31$ & $<0.001$ \\
Perioperative complications & $4(8.9 \%)$ & $5(4.4 \%)$ & 0.011 \\
Postoperative complications & $8(17.8 \%)$ & 0 & $<0.001$ \\
Postdischarge complications & $4(8.9 \%)$ & 0 & 0.011 \\
Conversion rate & $12(26.7 \%)$ & $2(2.2 \%)$ & $<0.001$ \\
Use of blood derivatives & $1(2.2 \%)$ & 0 & 0.333 \\
\hline
\end{tabular}

ESRD, end-stage renal disease; $\mathrm{N}$, those without ESRD.

treated without any complications and no additional intervention was needed. There was no mortality in either group. Hospital stay was $1.7 \pm 0.47$ days in the case group and $1.4 \pm 0.31$ in the control group $(p<0.001)$.

\section{Discussion}

The incidence of biliary stones does not increase in ESRD patients. Patients with ESRD have been regarded as being for surgery because of platelet dysfunction, activated fibrinolysis and impaired healing. In our study, there was significant more complications, higher conversion rates and longer hospital stay in ESRD group. Fortunately, these complications were easily handled without any serious morbidity or mortality. However, certain co-morbidities like hepatitis C virus (HCV) infection may change this opinion. In this group of patients, there are no additional risk factors when compared to the general population. It is an important cause of chronic liver disease and predispose to gallbladder stone among ESRD patients. Estimates of the prevalence of HCV antibodies in patients on hemodialysis (HD) in developed countries range from $7 \%$ to $40 \%$ and are higher in the developing countries of the world [8]. Hepatitis B, the other chronic viral infection of liver is seen in the ESRD patients. The prevalence of serum hepatitis B surface antigen (HBsAg) sero-positivity in HD patients is $0 \%-10 \%$ in the developed countries, and $2 \%-20 \%$ in the developing countries [9].

The incidence of active HCV disease is similar in both ESRD patients and general population (nearly 85\%) [10]. Approximately $60 \%$ of the patients on HD with HCV demonstrated histologic activity [11]. Hepatitis C infected patients treated with HD have depressed ALT levels, and 50\% - 65\% of them have normal aminotransferases unlike the non-ESRD population [12] [13]. Only 1/3 of those HD patients with biopsy proven hepatitis have abnormal transaminase levels. As a result, natural history of viral hepatitis chronic disease is mostly unknown [10].

Lowell et al. demonstrated a high prevalence of cholelithiasis in diabetic patients with ESRD (27.3\%) [14]. In this study group, more than $50 \%$ of the patients are diabetic. In contrast to the general literature, Kazama et al. argue that the risk of gallstone formation is higher in ESRD population except stage 5 than non-ESRD population [15].

Single dose prophylactic intravenous antibiotic is recommended in ESRD patients to decrease the peritonitis risk due to gallbladder perforation and spillage of bile and gallstones [16].

Data of this study group basically reflects the common laboratory and clinical characteristics of ESRD patients. These consist of lower hemoglobin levels, mild thrombocytopenia, elevated phosphatase, blood urea nitrogen, and creatinine values and normal coagulation profile and high American Society of Anesthesiologists scores. In this study, there is no difference between the groups in terms of usage of blood derivates due to hemorrhage. We conclude that in general, uremic bleeding which is widely known, is well-controlled with HD treatment thus bleeding tendency should not be a major problem. Similarly, bleeding is not a problem in CAPD patients in LC [15].

There is no consensus about the management of asymptomatic gallstone disease among the ESRD patients and no evidence was found for increased morbidity or mortality related to gallbladder disease. Cholecystectomy is indicated only in symptomatic cholelithiasis patients with ESRD, as in the general population [17]. 
In our study, statistically significant differences were found regarding perioperative complications between the two groups $(p=0.011)$. Gentle handling and grasping the gallbladder is important to avoid perforation. Friable gallbladders can be aspirated before starting the surgery. We aspirated three patients' gallbladders intraoperatively before we dissected Calot's triangle. Although four patients' gallbladders (two in each group) were perforated during the grasping, spillage of bile or stones did not occur.

Patients with ESRD have higher additional disease rate and greater ASA scores. The co morbidities are lengthened hospital stay after laparoscopic cholecystectomy in patients with ESRD; mean length of hospitalization is significantly higher for patients with ESRD than it is for patients without ESRD $(p<0.001)$.

Approximately 5\% to 15\% of the patients (without ESRD) undergoing laparoscopic cholecystectomy require conversion to open cholecystectomy for various reasons [17]-[19]. Twelve patients with ESRD (26.7\%) in this study required conversion to open cholecystectomy. The reason for conversion in 10 patients was related to intraabdominal adhesions that had consequently formed after recurrent episodes of peritonitis. The reason for conversion of the remaining two ESRD patients with hemodialysis was unable to display anatomy adequately in Calot's triangle. In this study, history of peritonitis was the most important reason for changing the operative procedure to an open one. Duration of ESRD or CAPD did not affect the conversion rate but the number of peritonitis episodes was important. In this study, converted cases had a history of at least 3 episodes of peritonitis. Roubicek et al. demonstrated that proinflammatory cytokines were increased in the visceral adipose tissue [20]. This may be another reason for dense adhesions that prevent LC. We have noted a significantly higher conversion rate in our case group but there is no CAPD history in Yeh's study group [6].

In the first cases with ESRD, operation time was higher compared to the general population due to limited laparoscopic experience. All patients in this study were operated on electively, and only one of them (2.2\%) needed blood derivatives.

Postoperative complications were seen only in the case group. Most of the postoperative complications seen in patients with ESRD were less severe and could be conservatively treated. Postoperatively, three patients (9\%) with abdominal wall hematomas were treated conservatively. Care must be taken when placing the trocars and when dissecting the gallbladder from the liver bed. Post discharge complications were treated clinically and resolved.

The limitations of this study were retrospective data collection and small number of patients. Therefore, we aimed compare two different populations; it is impossible to randomize between groups. Even though there was a non-randomized control group, this type of study protocol exactly serves to test our hypothesis.

\section{Conclusion}

In conclusion, laparoscopic cholecystectomy is feasible and safe for ESRD patients, and perioperative, postoperative, and postdischarge complications can be conservatively treated and are probably less severe than with an open procedure. The laparoscopic technique requires a certain level of experience. The limited number of patients used in this study will serve as a guide for other surgeons. Further studies with larger number of patients might have sufficient power to show statistically significant complication rates.

\section{References}

[1] Altiparmak, M.R., Pamuk, O.N., Pamuk, G.E., Celik, A.F., Apaydin, S., Cebi, D., Mihmanli, I. and Erek, E. (2003) Incidence of Gallstones in Chronic Renal Failure Patients Undergoing Hemodialysis: Experience of a Center in Turkey. The American Journal of Gastroenterology, 4, 813-820. http://dx.doi.org/10.1111/j.1572-0241.2003.07382.x

[2] Korzets, Z., Golan, E., Ben-Chitrit, S., Schneider, N., Chagnac, A., Carel, R. and Bernheim, J. (1998) Prevalence of Cholelithiasis in Non-Diabetic Haemodialysis and Continuous Ambulatory Peritoneal Dialysis Patients. Nephron, 1, 44-47. http://dx.doi.org/10.1159/000044881

[3] Hojs, R. (1995) Cholecystolithiasis in Patients with End-Stage Renal Disease Treated with Haemodialysis: A Study of Prevalence. American Journal of Nephrology, 1, 15-17. http://dx.doi.org/10.1159/000168796

[4] National Institutes of Health Consensus (1993) National Institutes of Health Consensus Development Conference Statement on Gallstones and Laparoscopic Cholecystectomy. American Journal of Surgical Pathology, 165, 390-398.

[5] Keus, F., de Jong, J.A., Gooszen, H.G. and van Laarhoven, C.J. (2006) Laparoscopic versus Open Cholecystectomy for Patients with Symptomatic Cholecystolithiasis. Cochrane Database of Systematic Reviews, 18, Article ID: CD006231.

[6] Yeh, C.N., Chen, M.F. and Jan, Y.Y. (2005) Laparoscopic Cholecystectomy for 58 End Stage Renal Disease Patients. 
Surgical Endoscopy, 19, 915-918. http://dx.doi.org/10.1007/s00464-004-2207-2

[7] Miles, A.M. and Friedman, E.A. (1997) Center and Home Hemodialysis: Outcome and Complication. In: Schrier, R.W. and Gottschalk, C.W., Eds., Diseases of the Kidney, Little Brown, Boston, 2807-2838.

[8] Martin, P. and Fabrizi, F. (2008) Hepatitis C Virus and Kidney Disease. Journal of Hepatology, 49, 613-624. http://dx.doi.org/10.1016/j.jhep.2008.06.003

[9] Fabrizi, F., Messa, P. and Martin, P. (2008) Hepatitis B Virus Infection and the Dialysis Patient. Seminars in Dialysis, 21, 440-446. http://dx.doi.org/10.1111/j.1525-139X.2008.00437.x

[10] Pol, S., Thiers, V., Carnot, F., Zins, B., Romeo, R., Berthelot, P. and Bréchot, C. (1995) Efficacy and Tolerance of Alpha-2b Interferon Therapy on HCV Infection of Hemodialyzed Patients. Kidney International, 47, 1412-1418. http://dx.doi.org/10.1038/ki.1995.198

[11] Chan, T.M. (1996) Hepatitis C Virus Infection in Patients on Renal Replacement Therapy. Nephrology, 2, S85-S87. http://dx.doi.org/10.1111/j.1440-1797.1996.tb00147.x

[12] Wolf, P.L., William, D., Coplon, N. and Coulson, A.S. (1972) Low Aspartate Transaminase Activity in Serum of Patients Undergoing Chronic Hemodialysis. Clinical Chemistry, 18, 567-573.

[13] Rostaing, L., Izopet, J., Cisterne, J.M., Icart, J., Chabannier, M.H., Panicali, H. and Durand, D. (1997) Prevalence of Antibodies to Hepatitis C Virus and Correlation with Liver Disease in Renal Transplant Patients. American Journal of Nephrology, 17, 46-52. http://dx.doi.org/10.1159/000169071

[14] Lowell, J.A., Stratta, R.J., Taylor, R.J., Bynon, J.S., Larsen, J.L. and Nelson, N.L. (1993) Cholelithiasis in Pancreas and Kidney Transplant Recipients with Diabetes. Surgery, 114, 858-863.

[15] Kazama, J.J., Kazama, S., Koda, R., Yamamoto, S., Narita, I. and Gejyo, F. (2009) The Risk of Gallbladder Stone Formation Is Increased in Patients with Predialysis Chronic Kidney Disease but Not Those Undergoing Chronic Hemodialysis Therapy. Nephron Clinical Practice, 111, c167-c172. http://dx.doi.org/10.1159/000199456

[16] Ekici, Y., Karakayali, F., Yagmurdur, M.C., Moray, G., Karakayali, H. and Haberal, M. (2009) Laparoscopic Cholecystectomy in Patients Undergoing Continuous Ambulatory Peritoneal Dialysis: A Case-Control Study. Surgical Laparoscopy, Endoscopy \& Percutaneous Techniques, 19, 101-105. http://dx.doi.org/10.1097/SLE.0b013e31819f32f5

[17] Jackson, T., Treleaven, D., Arlen, D., D’Sa, A., Lambert, K. and Birch, D.W. (2005) Management of Asymptomatic Cholelithiasis for Patients Awaiting Renal Transplantation. Surgical Endoscopy, 19, 510-513. http://dx.doi.org/10.1007/s00464-004-8817-x

[18] Peters, J.H., Krailadsiri, W., Incarbone, R., Bremner, C.G., Froes, E., Ireland, A.P., Crookes, P., Ortega, A.E., Anthone G.A. and Stain, S.A. (1994) Reasons for Conversion from Laparoscopic to Open Cholecystectomy in an Urban Teaching Hospital. The American Journal of Surgery, 168, 555-558. http://dx.doi.org/10.1016/S0002-9610(05)80121-7

[19] Rosen, M., Brody, F. and Ponsky, J. (2002) Predictive Factors for Conversion of Laparoscopic Cholecystectomy. The American Journal of Surgery, 184, 254-258. http://dx.doi.org/10.1016/S0002-9610(02)00934-0

[20] Roubicek, T., Bartlova, M., Krajickova, J., Haluzikova, D., Mraz, M., Lacinova, Z., Kudla, M., Teplan, V. and Haluzik, M. (2009) Increased Production of Proinflammatory Cytokines in Adipose Tissue of Patients with End-Stage Renal Disease. Nutrition, 25, 762-768. http://dx.doi.org/10.1016/j.nut.2008.12.012 
Scientific Research Publishing (SCIRP) is one of the largest Open Access journal publishers. It is currently publishing more than 200 open access, online, peer-reviewed journals covering a wide range of academic disciplines. SCIRP serves the worldwide academic communities and contributes to the progress and application of science with its publication.

Other selected journals from SCIRP are listed as below. Submit your manuscript to us via either submit@scirp.org or Online Submission Portal.
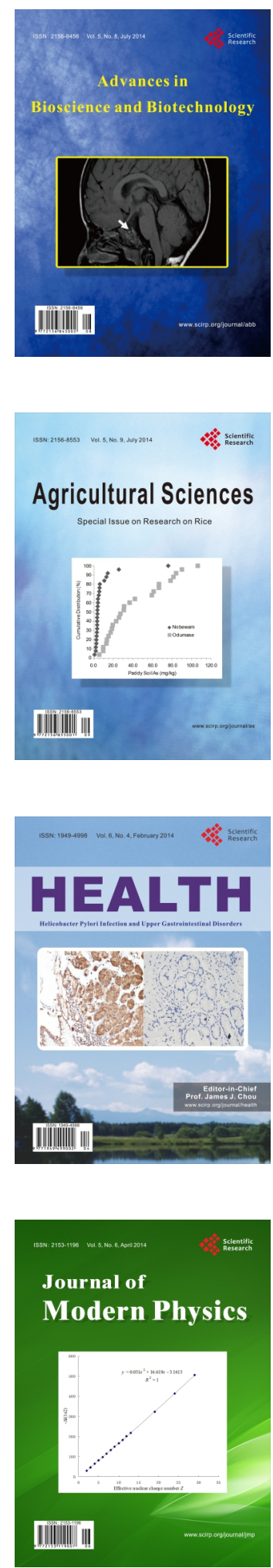
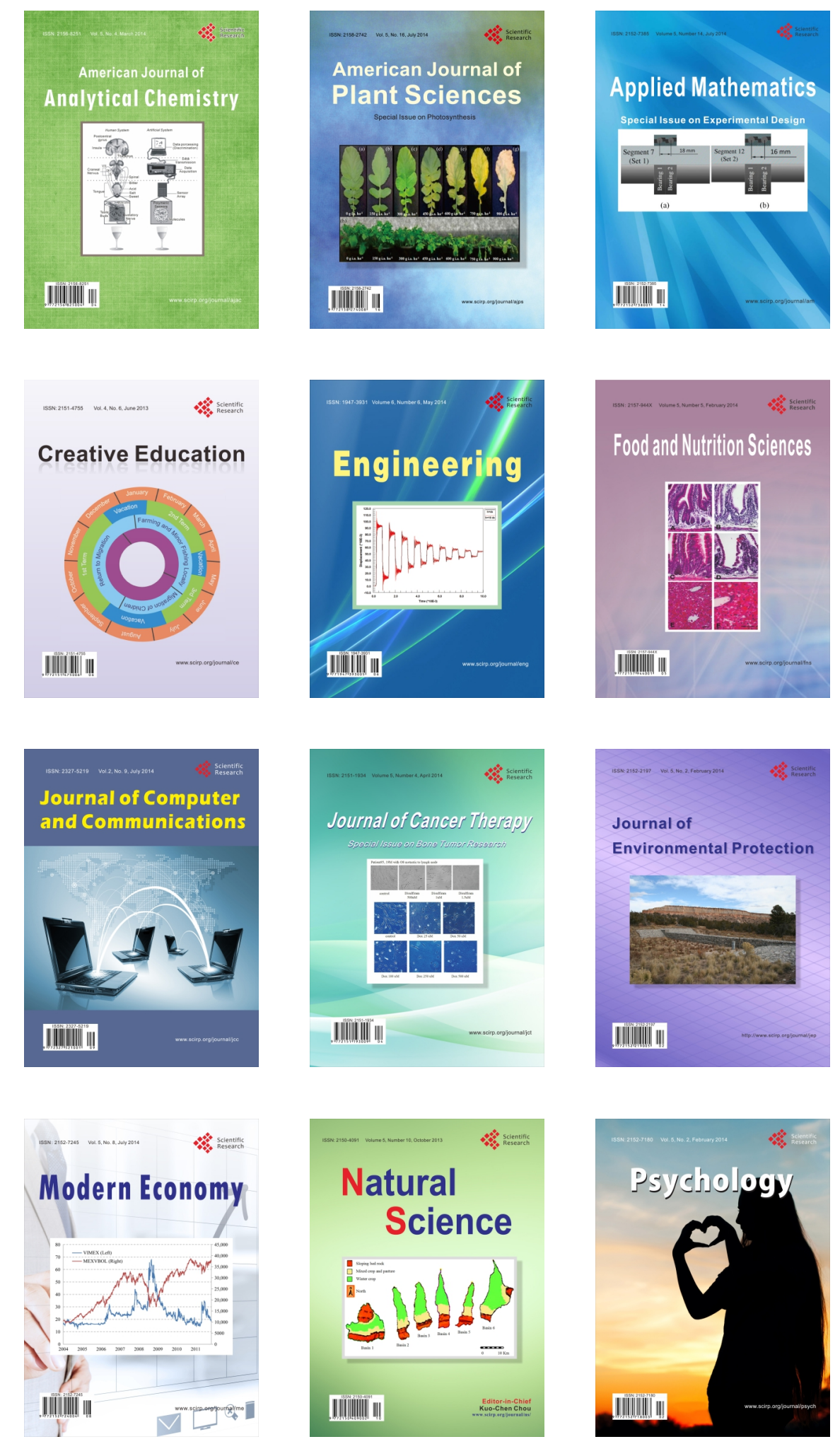